\title{
¿S Research Square

\section{Use of Prophylactic Iron Salts Supplementation During Gestation and Development of Gestational Diabetes Mellitus in Women From 2015 Pelotas (Brazil) Birth Cohort Study}

Vanessa Iribarrem Avena Miranda ( $\sim$ vanessairi@gmail.com )

Federal University of Pelotas

Tatiane da Silva Dal Pizzol

Federal University of Rio Grande do Sul

Marysabel Pinto Telis Silveira

Federal University of Pelotas

Sotero Serrate Mengue

Federal University of Rio Grande do Sul

Mariângela Freitas Silveira

Federal University of Pelotas

Bárbara H Lutz

Federal University of Pelotas

Romina Buffarini

Federal University of Pelotas

Andréa Dâmaso Bertoldi

Federal University of Pelotas

\section{Research Article}

Keywords: Pharmacoepidemiology, drug utilization, birth cohort study, gestational diabetes mellitus, supplementation.

Posted Date: September 27th, 2021

DOl: https://doi.org/10.21203/rs.3.rs-862873/v1

License: (c) (1) This work is licensed under a Creative Commons Attribution 4.0 International License. Read Full License 


\section{Abstract \\ Background}

This study aims to evaluate the association between the use of iron salts during the first two trimesters in non-anemic women and the development of gestational diabetes mellitus (GDM).

\section{Methods}

The study used maternal data from 2015 Pelotas Birth Cohort. All non-anemic women at 24th week ( $\mathrm{N}=$ 2463) were eligible for this study. GDM was self-reported by women. Crude and adjusted logistic regression were performed considering level of significance $=0.05$.

\section{Results}

Among the women studied, $69.7 \%$ were exposed to prophylactic iron supplementation in the two first trimesters of gestation. The prevalence of GDM among those exposed was $8.7 \%(95 \% \mathrm{Cl} 7.4-10.1)$ and among those who were not exposed was 9.3\% (CI95\% 7.4-11.6). Iron supplementation was not associated with increased risk of GDM in crude $(\mathrm{OR}=0.9 ; 95 \% \mathrm{Cl} 0,7-1,3)$ and adjusted analysis $(\mathrm{OR}=1.1$; $95 \% \mathrm{Cl} 0,8-1,6)$.

\section{Conclusions}

The results suggested that routine iron use in non-anemic pregnant women does not increase the risk of developing gestational diabetes. This evidence supports the existing national and international guidelines, whose recommendation is prophylactic iron supplementation for all pregnant women as soon as they initiate antenatal care in order to prevent iron deficiency anemia.

\section{Background}

Gestational Diabetes Mellitus (GDM) is a temporary condition, characterized by hyperglycemia, which occurs due to carbohydrate and glucose intolerance $(1,2)$. It begins for the first time during pregnancy and it usually, disappears shortly after delivery (1). Population estimates of hyperglycemia frequency in pregnancy are conflicting, because there are different criteria for GDM diagnosis, with prevalence varying from 1 to $18 \%$ of pregnant women in different populations and differences between guidelines $(2,3)$. In Latin America, for example, the $75 \mathrm{~g}$ 2-hour glucose test $>7.8 \mathrm{mmol} / \mathrm{L}$ or $>140 \mathrm{mg} / \mathrm{dL}$ is a diagnosis of GDM. In China,> $5.1 \mathrm{mmol} / \mathrm{L}$ or $>92 \mathrm{mg} / \mathrm{dL}$ sets GDM diagnosis(4).

GDM is responsible for many consequences in maternal-fetal health in the short and long term (3). The most common consequences among children are the increased risk of fetal macrosomia, neonatal 
hypoglycemia, shoulder dystocia, and hyperinsulinemia at birth. Mothers with GDM are at increased risk of preeclampsia, gestational hypertension, cesarean section, and polyhydramnios. In addition, there is an increased risk of fetal malformations, abortion, neonatal and perinatal mortality, as well as increased risk

of maternal mortality (5-8). In the long term, the maternal effect of GDM is the elevated risk for the development of metabolic syndrome and type 2 diabetes(9). For the child, there is almost double the risk of developing childhood obesity and metabolic syndrome, compared to children born from non-diabetic mothers (9).

Another very prevalent problem during pregnancy is iron deficiency anemia, reaching $42.0 \%$ of all pregnant women (10). In this sense, current guidelines from World Health Organization (WHO) and Brazilian Ministry of Health recommend, in addition to adequate diet, prophylactic (routine) iron supplementation for all pregnant women, in order to satisfy the physiological needs of this mineral (11, 12). However, this universal prophylactic supplementation has been questioned, because according to some authors, high iron intake may increase the risk of GDM, especially for those women with normal hemoglobin levels in early pregnancy $(13,14)$, which has been reported as an independent risk factor for DMG (15).

Findings regarding the association between the use of iron salts and the development of gestational diabetes are new and still inconclusive, therefore, further studies are necessary to disentangle the possible relationship between the use of iron salts and GDM. In this study we aimed to evaluate the association between the use of iron salts in non-anemic women in early pregnancy and the development of GDM in a cohort of births whose mothers were followed up since the antenatal period.

\section{Methods}

This paper uses data from antenatal and perinatal studies from Pelotas' Birth Cohort of 2015 (C2015), which was conducted in the city of Pelotas in southern Brazil. The study invited all women living in the urban area of Pelotas who gave birth, including stillbirths, in the five maternity hospitals of the city, between January 1 and December 31, 2015.

Mothers were interviewed at the maternity hospital a few hours after delivery and answered a standardized questionnaire. They answered questions about antenatal period: demographic, socioeconomic, biological and behavioural issues, along with characteristics of pregnancy, delivery and medication use, including folic acid, iron salts and other vitamins and minerals. Furthermore, $75 \%$ of mothers who participated in the perinatal study were followed since the antenatal period by this cohort. More details of the study can be found in the cohort profile paper (16).

The analyses in this article were performed with all mothers from a perinatal follow-up who were eligible for this study ( $\mathrm{N}=2463)$ (Fig. 1). Anaemic pregnant women before 24th week (with record of at least one hemoglobin test $<11 \mathrm{~g} / \mathrm{dL}$ in the pregnant woman's antenatal card), were not included in the analyses. 
For the outcome "gestational diabetes mellitus" self-reports were considered. The mothers answered the following question: "Did you have diabetes during pregnancy?", followed by other question: "Did you have diabetes before pregnancy?". Pregnant women who already had diabetes before becoming pregnant $(n=$ 44) were excluded. Self-reported information about mother's knowledge of GDM, in the immediate postpartum, was validated through a study previously carried out in Pelotas' maternity, with high specificity $(99.0 \%, 95 \% \mathrm{Cl}: 98.1 ; 99.6)$ and good sensitivity $73.0 \%(95 \% \mathrm{Cl}: 55.9 ; 86.2)(17)$.

The variables used in the analysis as possible confounding factors were: maternal age (collected in complete years and categorized as $\leq 19,20-29,30-46$ ); ethnicity (self-reported by mothers as white, black or other); parity (total number of deliveries, including stillbirths and current pregnancy; later categorized as 1, 2, 3 or 4 or more); mother's schooling (number of years of study, later categorized into four groups: $0-4,5-8,9-11$ and 12 or more years) and family income expressed in local currency and converted into a multiple of minimum wage at the time of the perinatal interview (categorized as $\leq 1,1.1$ to $3.0,3.1$ to $6.0,6.1$ to 10 and $>10$ ). A 'minimum wage' is a measure of the legal minimum monthly salary for formal employees in Brazil.

Family history of diabetes mellitus was reported by the mother at the 24-month follow-up, pre-pregnancy body mass index (BMI) was calculated by dividing pre-pregnancy weight by the square of maternal height, and categorised according to WHO criteria(18): underweight ( $\left.<18.5 \mathrm{~kg} / \mathrm{m}^{2}\right)$; normal (18.5-24.9 $\left.\mathrm{kg} / \mathrm{m}^{2}\right)$; overweight (25.0-29.9 kg/m²); and obese $\left(\geq 30 \mathrm{~kg} / \mathrm{m}^{2}\right)$ and smoking in pregnancy was considered "yes" when the mother reported smoking at least one cigarette a day, for at least 30 days.

Information regarding supplement use was taken from the following questions: " Have you used or are you using any vitamin, calcium, folic acid or iron salts since you became pregnant?". If yes, the drug names were then questioned and for each drug reported a question about the trimester of use was asked: "In which trimester of pregnancy did you use this medicine?" (1st trimester / 2nd trimester, 3rd trimester).

From these questions, it was possible to generate the main exposure used in our analyses: "use of prophylactic iron in the first and / or second trimester of pregnancy", which has been formulated using all iron compounds alone or in combination with other active substances, provided that iron was the main compound present. All analyses were performed in Stata software 15.0. Sample description was performed according to exposure and outcome (GDM) using the chi-square test. The association of iron supplements use with development of GDM was evaluated using logistic regression

The regression followed a previously established hierarchical conceptual model, which comprises three levels. The distal level included the sociodemographic variables and family history of diabetes; the second level included pre-gestational BMI, parity and smoke; and the proximal level included the use of iron salts. Variables with $p<0.20$ were kept in the model to control confounding factors. For all statistical analyses, the significance threshold was set at $p<0.05$.

The Federal University of Pelotas, School of Physical Education Ethics Committee, approved the study protocol (522.064). All mothers signed an informed consent form before being interviewed. 


\section{Results}

Of the 2463 mothers who participated in this study, about half were between 20 and 29 years old (48.0\%), most white skin colour (75.8\%) and with more than nine years of schooling (72.1\%). The predominant family income was 1.1 to 3 minimum wages (46.0\%) and $47.0 \%$ of the mothers had pre-gestational BMI considered normal by WHO criteria (18). More than half of women were in their first pregnancy $(52.7 \%)$, had no family history of gestational diabetes (55.5\%) and most were non-smokers (86.6\%) (Table 1$)$. 
Table 1

'Baseline characteristics of mothers participating in the perinatal cohort study $(n=4270)$ and eligible mothers $(n=2463)$. 2015 Pelotas (Brazil) Birth Cohort.

\begin{tabular}{|c|c|c|c|c|}
\hline \multirow[t]{2}{*}{ Variables } & \multicolumn{2}{|c|}{ Perinatal sample } & \multicolumn{2}{|c|}{ Eligible mothers } \\
\hline & $N(\%)$ & $95 \% \mathrm{Cl}$ & $N(\%)$ & $95 \% \mathrm{Cl}$ \\
\hline \multicolumn{5}{|l|}{ Age } \\
\hline$\leq 19$ & $630(14.8)$ & $13.7-15.8$ & $282(11.5)$ & $10.2-12.7$ \\
\hline $20-29$ & $2021(47.3)$ & $45.8-48.8$ & $1182(48.0)$ & $46.0-50.0$ \\
\hline $30-46$ & $1618(37.9)$ & $36.4-39.4$ & $998(40.5)$ & $38.5-42.4$ \\
\hline \multicolumn{5}{|c|}{ Skin colour } \\
\hline White & $3005(70.5)$ & $69.1-71.8$ & $1864(75.8)$ & $74.1-77.4$ \\
\hline Black & $680(16.0)$ & $14.8-17.1$ & $305(12.4)$ & $11.1-13.7$ \\
\hline Others & $578(13.5)$ & $12.5-14.5$ & $291(11.8)$ & $10.5-13.1$ \\
\hline \multicolumn{5}{|c|}{ Schooling (years) } \\
\hline$\leq 4$ & $394(9.3)$ & $8.3-10.1$ & $168(6.8)$ & $5.8-7.8$ \\
\hline $5-8$ & $1098(25.7)$ & $24.4-27.0$ & $520(21.1)$ & $19.5-22.7$ \\
\hline $9-11$ & $1463(34.3)$ & $32.8-35.7$ & $894(36.3)$ & $34.4-38.2$ \\
\hline$\geq 12$ & $1314(30.7)$ & $29.4-32.1$ & $881(35.8)$ & $33.9-37.6$ \\
\hline \multicolumn{5}{|c|}{ Family income (minimum wages) ${ }^{a}$} \\
\hline$\leq 1$ & $512(12.6)$ & $11.6-13.6$ & $222(9.5)$ & $8.3-10.6$ \\
\hline $1.1-3.0$ & $1906(47.0)$ & $45.4-48.5$ & $1077(46.1)$ & $44.0-48.0$ \\
\hline $3.1-6.0$ & $1077(26.5)$ & $25.2-27.9$ & $684(29.2)$ & $27.4-31.1$ \\
\hline $6.1-10.0$ & $307(7.5)$ & $6.6-8.2$ & $191(8.2)$ & $7.0-9.2$ \\
\hline$>10.0$ & $257(6.4)$ & $5.5-7.0$ & $164(7.0)$ & $5.9-8.1$ \\
\hline \multicolumn{5}{|c|}{ Pre-pregnancy body mass index $\left(\mathrm{kg} / \mathrm{m}^{2}\right)$} \\
\hline$<18.5$ & $155(3.8)$ & $0.3-4.3$ & $62(2.5)$ & $1.2-3.1$ \\
\hline
\end{tabular}

Cl: confidence interval

a Family income expressed in local currency and converted into a multiple of minimum wage $(\mathrm{R} \$ 788,00)$.

${ }^{b}$ Family history of diabetes mellitus. Variable with highest values of missing information $(n=675)$. 


\begin{tabular}{|c|c|c|c|c|}
\hline \multirow{2}{*}{$\begin{array}{l}\text { Variables } \\
18.5-<25.0\end{array}$} & \multicolumn{2}{|c|}{ Perinatal sample } & \multicolumn{2}{|c|}{ Eligible mothers } \\
\hline & $1037(49.3)$ & $47.8-50.8$ & $1150(47.5)$ & $45.5-49.5$ \\
\hline $25.0-<30.0$ & $1160(28.1)$ & $26.7-29.4$ & 717 (29.6) & $27.8-31.4$ \\
\hline$\geq 30.0$ & 778 (18.8) & $17.6-20.0$ & $490(20.2)$ & $18.6-21.8$ \\
\hline \multicolumn{5}{|l|}{ Parity } \\
\hline 1 & $2114(49.6)$ & $48.0-51.0$ & $1298(52.7)$ & $50.7-54.6$ \\
\hline 2 & $1315(30.8)$ & $29.4-32.2$ & 780 (31.7) & $29.8-33.5$ \\
\hline 3 & $472(11.0)$ & $10.1-12.0$ & $242(9.8)$ & $8.6-11.0$ \\
\hline$\geq 4$ & $367(8.6)$ & $7.7-9.4$ & $142(5.8)$ & $4.8-6.6$ \\
\hline \multicolumn{5}{|c|}{ Family History of GDM ${ }^{b}$} \\
\hline No & 1707 (55.9) & $54.2-57.8$ & $993(55.5)$ & $53.2-57.8$ \\
\hline Yes & $1345(44.1)$ & $42.2-45.8$ & 795 (44.4) & $42.2-46.7$ \\
\hline \multicolumn{5}{|l|}{ Smoke } \\
\hline No & $3553(83.3)$ & $82.1-84.3$ & $2132(86.6)$ & $85.2-87.9$ \\
\hline Yes & 714 (16.7) & $15.6-17.8$ & 330 (13.4) & $12.1-14.8$ \\
\hline \multicolumn{5}{|c|}{$\mathrm{Cl}$ : confidence interval } \\
\hline \multicolumn{5}{|c|}{$\begin{array}{l}\text { a Family income expressed in local currency and converted into a multiple of minimum wage } \\
(\mathrm{R} \$ 788,00) \text {. }\end{array}$} \\
\hline
\end{tabular}

Women eligible for this study did not differ from women participating in the perinatal study of C2015 regarding the characteristics analysed (Table 1).

Of all women in the analysed sample $(\mathrm{N}=2463), 69.7 \%$ were exposed to iron supplementation in the first and / or second trimester of pregnancy. The prevalence of GDM was higher among older pregnant women (12.8\%), less educated (13.7\%), with family income between 1.1 and 3.0 minimum / monthly salaries $(10.2 \%)$. Pre-pregnancy BMI > $=30(16.9 \%)$, who had 4 or more children (12.6\%) and with a family history of diabetes (12.5\%) (Table 2). 
Table 2

Prevalence of gestational diabetes mellitus (GDM) according to independent variables $(N=2463) .2015$ Pelotas (Brazil) Birth Cohort.

\begin{tabular}{|c|c|c|c|c|}
\hline \multirow[t]{2}{*}{ Variables } & \multicolumn{4}{|c|}{ Prevalence of DMG } \\
\hline & $\mathbf{N}$ & $\%$ & $95 \% \mathrm{Cl}$ & p-value ${ }^{a}$ \\
\hline Age & & & & $<0.001$ \\
\hline$\leq 19$ & 6 & 2,1 & $0.9-4.6$ & \\
\hline $20-29$ & 84 & 7.1 & $5.7-8.7$ & \\
\hline $30-46$ & 128 & 12.8 & $10.8-15.1$ & \\
\hline Skin colour & & & & 0.202 \\
\hline White & 156 & 8.4 & $7.1-9.7$ & \\
\hline Black & 35 & 11.4 & $8.3-15.6$ & \\
\hline Others & 27 & 9.2 & $6.4-13.2$ & \\
\hline Schooling (years) & & & & 0.004 \\
\hline$\leq 4$ & 23 & 13.7 & $9.2-19.8$ & \\
\hline $5-8$ & 37 & 7.1 & $5.1-9.6$ & \\
\hline $9-11$ & 95 & 10.6 & $8.7-12.8$ & \\
\hline$\geq 12$ & 63 & 7.2 & $5.6-9.1$ & \\
\hline Family income (minimum wages) ${ }^{b}$ & & & & 0.002 \\
\hline$\leq 1$ & 19 & 8.5 & $5.5-13.0$ & \\
\hline $1.1-3.0$ & 110 & 10.2 & $8.6-12.2$ & \\
\hline $3.1-6.0$ & 68 & 9.9 & $7.9-12.4$ & \\
\hline $6.1-10.0$ & 8 & 4.2 & $2.1-8.1$ & \\
\hline$>10.0$ & 4 & 2.4 & $0.9-6.3$ & \\
\hline
\end{tabular}

Cl: confidence interval

a $p$ value of chi-square test

${ }^{\mathrm{b}}$ Family income expressed in local currency and converted into a multiple of minimum wage $(\mathrm{R} \$ 788,00)$

${ }^{c}$ Family history of diabetes mellitus gestational. Variable with highest values of missing information $(n=675)$. 


\begin{tabular}{|c|c|c|c|c|}
\hline Variables & \multicolumn{4}{|c|}{ Prevalence of DMG } \\
\hline \multicolumn{4}{|l|}{ Pre-pregnancy body mass index $\left(\mathrm{kg} / \mathrm{m}^{2}\right)$} & \multirow[t]{2}{*}{$<0.001$} \\
\hline$<18.5$ & 1 & 1.6 & $0.2-11.1$ & \\
\hline $18.5-<25.0$ & 61 & 5.3 & $4.1-6.7$ & \\
\hline $25.0-<30.0$ & 70 & 9.7 & 7.7-12.1 & \\
\hline$\geq 30.0$ & 83 & 16.9 & $13.8-20.5$ & \\
\hline \multicolumn{4}{|l|}{ Parity } & \multirow[t]{2}{*}{$<0.001$} \\
\hline 1 & 83 & 6.4 & $5.1-7.8$ & \\
\hline 2 & 87 & 11.2 & $9.1-13.5$ & \\
\hline 3 & 30 & 12.4 & $8.7-17.2$ & \\
\hline$\geq 4$ & 18 & 12.6 & $8.0-19.3$ & \\
\hline \multicolumn{4}{|l|}{ Family History of GDMc } & \multirow[t]{3}{*}{$<0.001$} \\
\hline No & 77 & 7.8 & $6.2-9.6$ & \\
\hline Yes & 100 & 12.5 & $10.4-15.1$ & \\
\hline \multicolumn{4}{|l|}{ Smoke } & \multirow[t]{3}{*}{0.644} \\
\hline No & 191 & 8.9 & $7.8-10.2$ & \\
\hline Yes & 27 & 8.1 & $5.6-11.6$ & \\
\hline \multicolumn{4}{|l|}{ Iron supplementation } & \multirow[t]{2}{*}{0.626} \\
\hline No & 68 & 9.3 & $7.4-11.5$ & \\
\hline Yes & 146 & 8.7 & $7.4-10.1$ & \\
\hline Total & 214 & 8.8 & $7.7-10.0$ & \\
\hline \multicolumn{5}{|l|}{ Cl: confidence interval } \\
\hline \multicolumn{5}{|l|}{ a $p$ value of chi-square test } \\
\hline \multicolumn{5}{|c|}{$\begin{array}{l}\text { b Family income expressed in local currency and converted into a multiple of minimum wage } \\
(\mathrm{R} \$ 788,00)\end{array}$} \\
\hline \multicolumn{5}{|c|}{$\begin{array}{l}{ }^{c} \text { Family history of diabetes mellitus gestational. Variable with highest values of missing information } \\
(n=675) \text {. }\end{array}$} \\
\hline
\end{tabular}

The prevalence of self-reported GDM in the entire cohort $(\mathrm{N}=4270)$ was $8.5 \%(95 \% \mathrm{Cl} 7.6 ; 9.3)$ and among those eligible for this study was $8.8 \%(95 \% \mathrm{Cl} 7.7 ; 10.0)$, being $8.6 \%(95 \% \mathrm{Cl} 7.3 ; 10.0)$ among 
exposed and $9.2 \%(95 \% \mathrm{Cl} 8.9 ; 9.2)$ among those not exposed to iron supplements (Table 2).

The use of iron salts in the first or second gestational trimester showed no positive association with GDM both in the crude analysis ( $\mathrm{OR}=0.995 \% \mathrm{Cl} 0.6 ; 1.3)$ and in the adjusted analysis for skin colour, age, education, family income, pre-gestational BMI, parity, family history of diabetes mellitus and smoking during pregnancy $(\mathrm{OR}=1.195 \% \mathrm{Cl} 0.8 ; 1.5)$ (Table 3$)$.

Table 3

Association between iron salt supplementation and gestational diabetes mellitus among non-anemic women. 2015 Pelotas (Brazil) Birth Cohort.

\begin{tabular}{|c|c|c|c|c|}
\hline \multirow[t]{2}{*}{ Iron supplementation } & \multicolumn{2}{|l|}{ Crude } & \multicolumn{2}{|l|}{ Adjusted $^{a}$} \\
\hline & OR (95\% Cl) & $\begin{array}{l}\mathrm{p}- \\
\text { value }\end{array}$ & OR $(95 \% \mathrm{Cl})$ & $\begin{array}{l}\text { p- } \\
\text { value }\end{array}$ \\
\hline $\begin{array}{l}\text { Non-anaemic pregnant women up to 24th weeks } \\
(\mathrm{N}=2463)\end{array}$ & & 0.509 & & 0.420 \\
\hline No & $\begin{array}{l}\text { Reference } \\
(1.0)\end{array}$ & & $\begin{array}{l}\text { Reference } \\
(1.0)\end{array}$ & \\
\hline Yes & $\begin{array}{l}0.9(0.7- \\
1.3)\end{array}$ & & $\begin{array}{l}1.1(0.8- \\
1.6)\end{array}$ & \\
\hline $\begin{array}{l}\text { Non-anaemic pregnant women up to } 12 \text { th weeks } \\
(\mathrm{N}=2559)\end{array}$ & & 0.631 & & 0.405 \\
\hline No & $\begin{array}{l}\text { Reference } \\
(1.0)\end{array}$ & & $\begin{array}{l}\text { Reference } \\
(1.0)\end{array}$ & \\
\hline Yes & $\begin{array}{l}1.1(0.8- \\
1.6)\end{array}$ & & $\begin{array}{l}1.2(0.8- \\
1.7)\end{array}$ & \\
\hline \multicolumn{5}{|l|}{ OR: odds ratio } \\
\hline $\begin{array}{l}\text { a Model adjusted for skin color, age, education, fa } \\
\text { BMI, parity, smoking during pregnancy, family his }\end{array}$ & $\begin{array}{l}\text { income in } \mathrm{mi} \\
\text { of diabetes } \mathrm{m}\end{array}$ & $\begin{array}{l}\text { mum n } \\
\text { litus. }\end{array}$ & jes, pre-gestat & \\
\hline
\end{tabular}

A subset of analyses was performed for data corresponding to the first trimester of pregnancy (up to 12th weeks). Results were similar from those derived from the main analyses (including the first and/or second trimester (adjusted OR $=1.295 \% \mathrm{Cl} 0.8 ; 1.7$ ) (Table 3).

\section{Discussion}

This study showed that, among non-anemic women, prophylactic use of iron in the first and/or second trimester of pregnancy was not an independent risk factor for the development of GDM

Published evidence on this subject is controversial. Previous observational studies have suggested that higher stores of iron might be associated with glucose metabolism disorders and an increase in the risk 
of GDM(19-24). This relation is biologically plausible, because iron has a high capacity of oxirreduction and its free form can catalyze the formation of free radicals, causing cell damage, also known as oxidative stress. Therefore, other suggested mechanism involves the formation of hidroxil radical which can damage the cell membranes of pancreatic $ß$ cells, affecting insulin synthesis and secretion associated with pregnancy-induced insulin resistance $(25,26)$. Also, the excess of iron deposition in the muscle may decrease glucose uptake (26). However, three randomized controlled trials, performed in hospitals and primary care services in China $(N=1164)(27)$, Finland $(N=2912)(28)$ and United Arab Emirates $(N=960)(29)$, found no significant difference in the incidence of GDM between control and experimental women. The daily iron dose in the experimental group ranged from $30 \mathrm{mg}$ to $60 \mathrm{mg}$ administered during the first and second gestational trimesters (28-30). In the control group two studies used placebo $(28,30)$ and one used a lower dosage of iron and a frequency of use lower than the experimental group (29). It should be noted that one of the randomized clinical trials cited (27) reported poor adherence to supplementation, which is a reality among pregnant women, mainly due to the undesirable adverse effects of iron supplementation (31), a fact that may alter the results of this and other researches, underestimating the real effect of this compound.

In our study no differences were found in the prevalence of GDM between women exposed and not exposed to the supplement, as in the study of Chan et al., 2009(27), who did not find increased incidence of GDM in the exposed group. The analysis of the study association may be limited due to lack of information regarding dosage, adherence, frequency of use and exposure time. Dosage information would be useful for qualifying the exposure variable (use of iron salts), considering "yes" only those compounds with prophylactic dosage. Knowledge of adherence to iron salt compounds would allow a better selection of women eligible for the study, and exposure time would be useful for estimating doseresponse effect.

Regardless of the findings concerning the occurrence of GDM and iron use, it is a fact that GDM has been increasing in several countries as a result of population growth, increased maternal age, lack of physical activity and, especially, the increased prevalence of obesity $(3,32)$, and our findings confirm this trend, presenting prevalence of self-reported gestational diabetes almost three times higher than $(8.5 \%$; IC $=7.8$; 9.6) another birth cohort study conducted in the year 2004, also in the city of Pelotas, with 4231 pregnant women, which found a self-reported prevalence of $3.0 \%$ gestational diabetes $(95 \% \mathrm{Cl}: 2.53 ; 3.64)(33)$. It is known that there are many divergences between the diagnostic criteria used for GDM, but between 2004 and 2015 there were no changes in the diagnostic test cut-offs in the recommendations from Brazilian Ministry of Health $(12,34)$.

Among the limitations of this study, it should be noted that many pregnant women had only one or two hemoglobin results in the antenatal card, thus, pregnant women who had only one recorded hemoglobin test whose result was normal (non-anaemic), were eligible for our study. However, they may have developed anaemia later and such information was not registered in the card. On the other hand, the use of information from antenatal records completed by health professionals who followed this pregnant women was a positive aspect and considered indispensable for the definition of women eligible for the 
study, since these results enabled the identification of non-anemic pregnant women according to the gestational trimester, which guaranteed the temporality of the study association.

Information on GDM diagnostic and iron use was self-reported only, which can be considered other limitations of this study. Furthermore, the control variable "family history of diabetes", was collected only from the third month of the 24-month follow-up of the children, which resulted in a high number of missing information (27.4\%).

Among the positive aspects, we highlight the fact that all pregnant women who had a hospital delivery in the municipality were interviewed within one year, and the small number of refusals, which allows the generalization of the results to other pregnant women under the same conditions of our sample.

\section{Conclusions}

Our study showed that the use of iron supplementation in non-anaemic pregnant women was not related with the development of GDM, which meets current national and international guidelines, whose recommendation is the routine supplementation to all pregnant women as soon as they start antenatal care to prevent iron deficiency anaemia.

\section{List Of Abbreviations}

Gestational diabetes mellitus (GDM)

World Health Organization (WHO)

Body mass index (BMI)

\section{Declarations}

Ethics approval and consent to participate: The Federal University of Pelotas, School of Physical Education Ethics Committee, approved the study protocol (approval number 522.064). All mothers signed an informed consent form before being interviewed. All methods were carried out in accordance with relevant guidelines and regulations.

Consent for publication: Not applicable.

Availability of data and materials: Due to confidentiality restrictions related to the ethics approval for this study, no identifying information about participants may be released. Dataset without identification used during the current study are available from the corresponding author on reasonable request.

Competing interests: none to declare 
Funding: This article is based on data from the study "Pelotas Birth Cohort, 2015" conducted by Postgraduate Program in Epidemiology at Federal University of Pelotas, with the collaboration of the Brazilian Public Health Association (ABRASCO). The 2015 Pelotas (Brazil) Birth Cohort is funded by the Wellcome Trust (095582). Funding for specific follow-up visits was also received from the Conselho Nacional de Desenvolvimento Científico e Tecnológico (CNPq) and Fundação de Amparo à Pesquisa do Estado do Rio Grande do Sul (FAPERGS). This study was financed in part by the Coordenação de Aperfeiçoamento de Pessoal de Nível Superior - Brasil (CAPES) - Finance Code 001.

Author Contributions: conceptualization, VIAM, MPTS, TSDP and ADB; methodology, VIAM, MPTS, SSM, BHL and ADB; formal analysis, VIAM, MPTS, RB and ADB; writing-original draft preparation, VIAM; writing-review and editing, VIAM, MPTS, TSDP, MSF, SSM, BHL, RB and ADB; supervision, MPTS, TSDP and $A D B$; project administration, ADB and MFS. All authors have read and approved the manuscript.

Acknowledgements: We are grateful to all the families who took part in the Pelotas birth cohorts, and the Pelotas teams, including research scientists, interviewers, workers and volunteers.

\section{References}

1. World Health Organization. Diagnostic criteria and classification of hyperglycaemia first detected in pregnancy: a World Health Organization Guideline. Diabetes Res Clin Pract. 2013.

2. American Diabetes Association. Diagnosis and classification of diabetes mellitus. Diabetes Care. 2012.

3. Diabetes OP-AdSMdSFBdAdGeOSBd. Rastreamento e diagnóstico de diabetes mellitus gestacional no Brasil. Brasília, DF: OPAS. 2016.

4. HodM K, Sacks D, Hadar E, Agarwal M, Di Renzo G. The International Federation of Gynecology and Obstetrics (FIGO) Initiative on gestational diabetes mellitus: A pragmatic guide for diagnosis, management, and care. Int J Gynaecol Obstet. 2015;131(Suppl 3):S173-S211.

5. Saúde. Md. Pré-natal e Puerpério. Atenção qualificada e humanizada. Manual técnico. 2006;5.

6. Simmons D. Diabetes and obesity in pregnancy. Best Pract Res Clin Obstet Gynaecol. 2011;25(1):25-36.

7. Metzger BE, Lowe LP, Dyer AR, Trimble ER, Chaovarindr U, Coustan DR, et al. Hyperglycemia and adverse pregnancy outcomes. N Engl J Med. 2008;358(19):1991-2002.

8. Balsells M, Garcia-Patterson A, Gich I, Corcoy R. Maternal and fetal outcome in women with type 2 versus type 1 diabetes mellitus: a systematic review and metaanalysis. J Clin Endocrinol Metab. 2009;94(11):4284-91.

9. Reece EA, Leguizamon G, Wiznitzer A. Gestational diabetes: the need for a common ground. Lancet. 2009;373(9677):1789-97.

10. Organization WH. Worldwide prevalence of anaemia 1993-2005: WHO global database on anaemia. 2008. 
11. Organization WH. Guideline: daily iron and folic acid supplementation in pregnant women: World Health Organization; 2012.

12. Saúde Md. Atenção ao pré-natal de baixo risco. Cadernos de Atenção Básica, n 32. 2013.

13. Helin A, Kinnunen TI, Raitanen J, Ahonen S, Virtanen SM, Luoto R. Iron intake, haemoglobin and risk of gestational diabetes: a prospective cohort study. BMJ open. 2012;2(5):e001730.

14. Milman N. Iron prophylaxis in pregnancy-general or individual and in which dose? Ann Hematol. 2006;85(12):821-8.

15. Lao TT, Chan Ly Fau - Tam KF, Tam Kf Fau - Ho LF, Ho LF. Maternal hemoglobin and risk of gestational diabetes mellitus in Chinese women. (0029-7844 (Print)).

16. Hallal PC, Bertoldi AD, Domingues MR, Silveira MFD, Demarco FF, da Silva ICM, et al. Cohort Profile: The 2015 Pelotas (Brazil) Birth Cohort Study. International journal of epidemiology. 2017.

17. Dode MA, Santos IS. [Validity of self-reported gestational diabetes mellitus in the immediate postpartum]. Cad Saude Publica. 2009;25(2):251-8.

18. WHO. Obesity and overweight 2016 [cited 2016. Available from: https://www.who.int/gho/ncd/risk_factors/overweight/en/.

19. Ardabili NS, Kariman N, Fathali AH, Alavi Majd H. Hemoglobin level during the first trimester of pregnancy in gestational diabetes. Ginekol Pol. 2012;83(12):929-33.

20. Lao TT, Chan LY, Tam KF, Ho LF. Maternal hemoglobin and risk of gestational diabetes mellitus in chinese women. Obstet Gynecol. 2002;99(5):807-12.

21. Javadian P, Alimohamadi S, Gharedaghi MH, Hantoushzadeh S. Gestational diabetes mellitus and iron supplement; effects on pregnancy outcome. Acta Medica Iranica. 2014;52(5):385.

22. Ozyigit EA, Ugur M, Unlu S, Ozaksit G, Avsar F. The Effect of Oral Iron Supplementation on the Glucose Metabolism in Non-Anemic Pregnant Women: A Prospective Case-Control Study. UhodUluslararasi Hematoloji-Onkoloji Dergisi. 2008;18(3):155-62.

23. Rawal S, Hinkle SN, Bao W, Zhu Y, Grewal J, Albert PS, et al. A longitudinal study of iron status during pregnancy and the risk of gestational diabetes: findings from a prospective, multiracial cohort. Diabetologia. 2017;60(2):249-57.

24. Fernandez-Cao JC, Aranda N, Ribot B, Tous M, Arija V. Elevated iron status and risk of gestational diabetes mellitus: A systematic review and meta-analysis. Matern Child Nutr. 2017;13(4).

25. Casanueva E, Viteri FE. Iron and oxidative stress in pregnancy. J Nutr. 2003;133(5 Suppl 2):1700s-8s.

26. Liu Q, Sun L, Tan Y, Wang G, Lin X, Cai L. Role of iron deficiency and overload in the pathogenesis of diabetes and diabetic complications. Curr Med Chem. 2009;16(1):113-29.

27. Chan K, Chan B, Lam K, Tam S, Lao T. Iron supplement in pregnancy and development of gestational diabetes-a randomised placebo-controlled trial. BJOG: An International Journal of Obstetrics \& Gynaecology. 2009;116(6):789-98.

28. Kinnunen TI, Luoto R, Helin A, Hemminki E. Supplemental iron intake and the risk of glucose intolerance in pregnancy: re-analysis of a randomised controlled trial in Finland. Maternal and Child 
Nutrition. 2016;12(1):74-84.

29. Ouladsahebmadarek E, Sayyah-Melli M, SiminTaghavi, Abbasalizadeh S, Seyedhejazie M. The effect of supplemental iron elimination on pregnancy outcome. Pak J Med Sci. 2011;27(3):641-5.

30. Chan KKL, Chan BCP, Lam KF, Tam S, Lao TT. Iron supplement in pregnancy and development of gestational diabetes-a randomised placebo-controlled trial. Bjog-an International Journal of Obstetrics and Gynaecology. 2009;116(6):789-98.

31. Titilayo A, Palamuleni ME, Omisakin O. Sociodemographic factors influencing adherence to antenatal iron supplementation recommendations among pregnant women in Malawi: Analysis of data from the 2010 Malawi Demographic and Health Survey. Malawi medical journal: the journal of Medical Association of Malawi. 2016;28(1):1-5.

32. Gestacional SBdDD. Diretrizes da Sociedade Brasileira de Diabetes. 2016.

33. Dode MA, Santos Ida S. [Risk factors for gestational diabetes mellitus in the birth cohort in Pelotas, Rio Grande do Sul State, Brazil, 2004]. Cad Saude Publica. 2009;25(5):1141-52.

34. Assistência pré-natal: normas e manuais técnicos., (1998).

\section{Figures}


Women from perinatal study $\mathrm{N}=4270$

Pregnant women with antenatal card and hemoglobin registration $\mathrm{N}=3419$

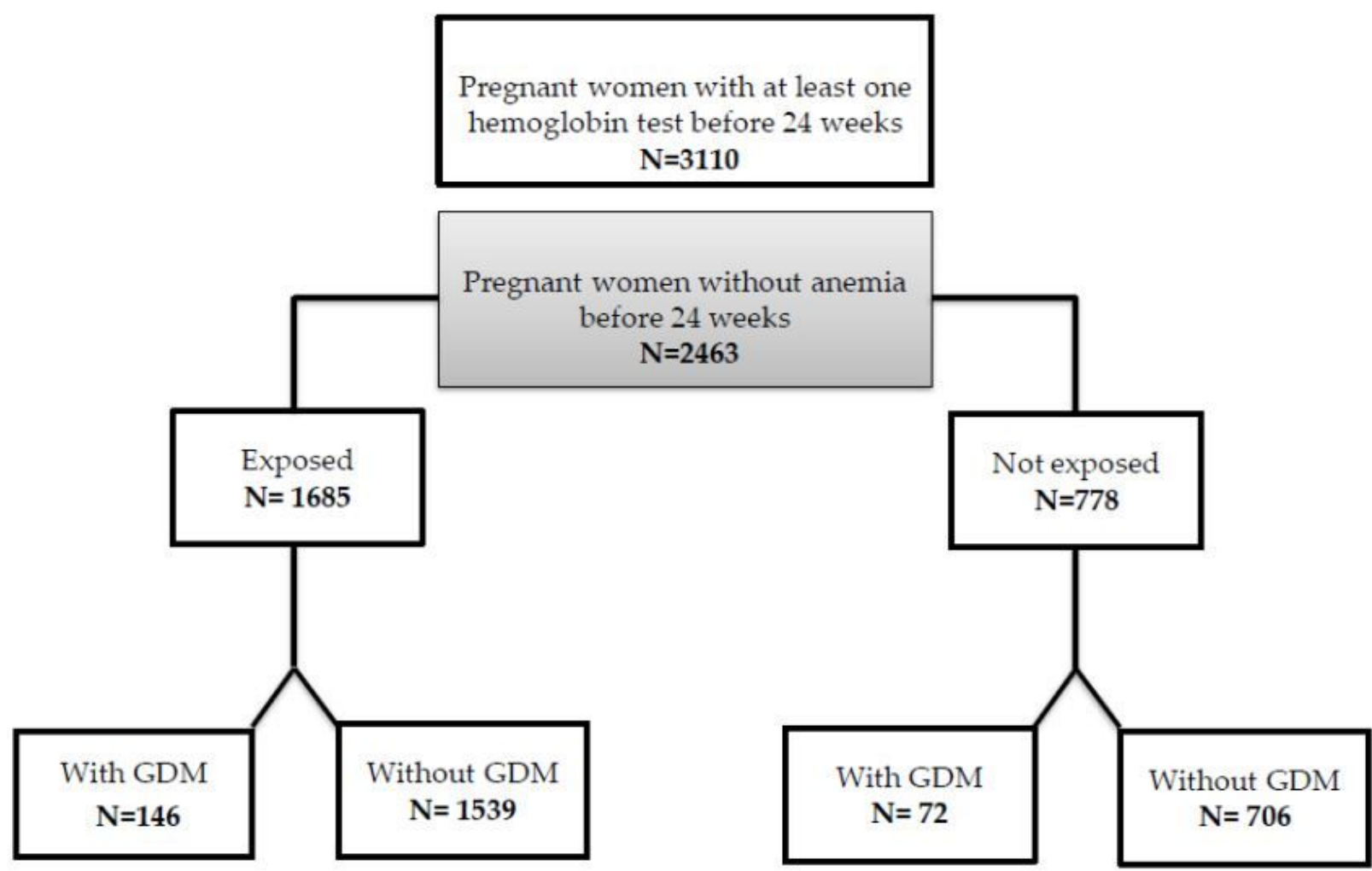

\section{Figure 1}

Flowchart of the study population of eligible women. 2015 Pelotas (Brazil) Birth Cohort. 